\title{
TIGA KONSEP PENDIDIKAN MENURUT AL-QUR'AN
}

\author{
Mahani. A \\ Institut Agama Islam Negeri Palu \\ Email:mahani@gmail.com
}

\begin{abstract}
This paper intends to describe three concepts of education according to the Qur'an which consist of ta'lim, ta'dib and tarbiyyah. Of course in the Koran these three words contain the meaning of education, but it needs to be emphasized that these words have their own meaning. This paper will reveal this by using a linguistic approach, the author will explain it comprehensively from various kinds of interpretations. The method used in this paper is the library research method or literature study. In conclusion, the concept of education according to the Koran is unique. The words at-tarbiyat, at-ta'lim, and at-ta'dib show a concept of education in these three concepts that complement each other and are included in educational goals that cannot be separated from one another.
\end{abstract}

Key Words: Ta'lim, Ta'dib, and Tarbiyyah.

\section{Abstrak}

Tulisan ini ingin menjabarkan tiga konsep pendidikan menurut al-Qur'an yang terdiri dari ta'lim, ta'dib dan tarbiyyah. Tentu saja dalam al-Qur'an tiga kata ini mengandung arti pendidikan, akan tetapi perlu ditegaskan kata-kata tersebut mempunyai makna yang tersendiri. Tulisan ini akan mengungkapkan hal tersebut dengan menggunakan pendekatan kebahasaan, penulis akan menjelaskannya secara komprehensif dari berbagai macam tafsir. Metode yang digunakan dalam tulisan ini yaitu metode library research atau studi kepustakaan. Dalam kesimpulannya Konsep tentang pendidikan menurut Alquran ini 
ternyata memiliki keunikan. Kata at-tarbiyat, at-ta'lim, dan atta'dib menunjukkan satu konsep pendidikan dalam ketiga konsep ini saling melengkapi dan tercakup dalam tujuan pendidikan yang tidak bisa dicerai pisahkan satu sama lain.

Kata Kunci: Ta'lim, Ta'dib, dan Tarbiyyah.

\section{Pendahuluan}

Alquran adalah kalamullah. Hal ini seperti dijelaskan oleh Allah dalam Alquran surah At Taubah ayat 6 .

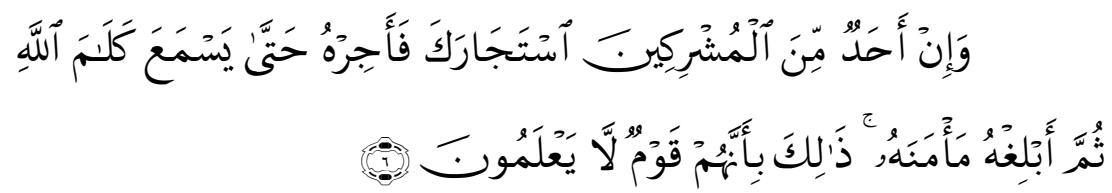

Terjemahnya : dan jika seorang diantara orang-orang musyrikin itu meminta perlindungan kepadamu, Maka lindungilah ia supaya ia sempat mendengar firman Allah, kemudian antarkanlah ia ketempat yang aman baginya. demikian itu disebabkan mereka kaum yang tidak mengetahui.

Selanjutnya Allah menjelaskan bahwa Dialah yang menurunkan Alquran dan Dia juga yang menjagaNya. Hal itu sebagaimana dijelaskan oleh Allah dalam Alquran surah Al Hijr ayat 9 .

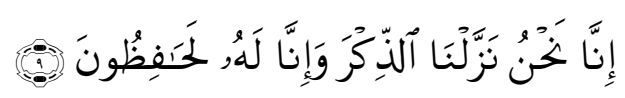

Terjemahnya : Sesungguhnya Kami-lah yang menurunkan Al Quran, dan Sesungguhnya Kami benar-benar memeliharanya

Tujuan Allah menurunkan Alquran adalah untuk dijadikan petunjuk bagi orang yang bertaqwa.Hal itu sebagaimana dijelaskan oleh Allah dalam Q.SAl Baqarah ayat 2. 


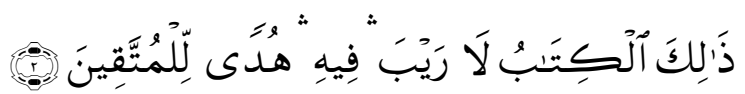

Terjemahnya : Kitab (Al Quran) ini tidak ada keraguan padanya; petunjuk bagi mereka yang bertaqwa,

Alquran sebagai jaminan ketentaraman hidup didunia dan kehidupan di akhirat sebagaimana sabda nabi. ${ }^{1}$

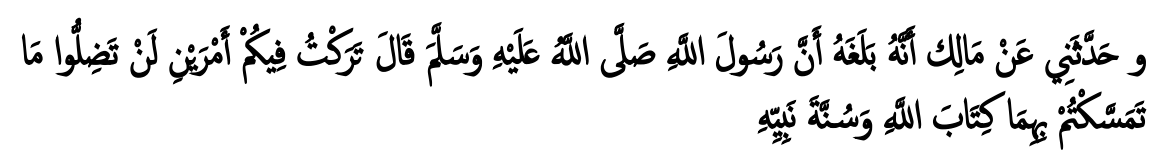

Artinya : dan dari Malik sesungguhnya Rasulullah saw bersabda: Aku Tinggalkan kepada kalian (maksudnya umat manusia) dua perkara. Kalian tidak akan tersesat selamanya jika kamu berpegang teguh kepada keduanya yaitu Alquran dan Sunnah nabinya.

Apa yang dipaparkan di atas adalah jaminan tentang orsinilitas Alquran adalah Kitab yang berasal dari Allah Swt.sebagai petunjuk bagi umat manusia dalam menjalani kehidupan di dunia maupun kehidupan di akhirat. Alquran sebagai petunjuk perlu dikaji, perlu dikembangkan dan diambil manfaatnya. Usaha mengkaji, mengembangkan dan mengambil manfaat dari Alquran diperlukan sebuah sistem kerja yang disebut kerja pendidikan. Artinya Firman Allah ini akan bermanfaat bagi umat manusia dan berkembang serta terpelihara dari penyimpangan jika melalui suatu usaha penjagaan yang bersifat ilmiah dan berkesinambungan yakni melalui kegiatan lembaga pendidikan.

Sebuah ide atau gagasan akan tetap eksis di tengah-tengah umat manusia jika ide atau gagasan tersebut dirasakan manfaatnya. Alquran sebagai kalamullah tentunya manfaatnya melampaui dari gagasan dan konsep yang dibuat akal manusia. Untuk itu perlu

${ }^{1}$ Malik bin Annas, Muwatta Imam Malik (Madinah: Darul Al-Ghad alJadid, 2005), h. 254. 
dikaji secara terus menerus untuk menemukan manfaatnya sesuai dengan kemajuan ilmu pengetahuan dan teknologi.

Al-Qur'an sebagai petunjuk berdasarkan aspek ini maka kajian terhadap konsep pendidikan menurut Alquran menjadi urgen mengingat konsep-konsep pendidikan dalam Alquran akan lebih sesuai dengan fitrah manusia karena merupakan konsep yang dibuat langsung oleh Allah Swt. Untuk merealisasikan maksud tersebut kajian ini akan diarahkan kepada tiga istilah yang terdapat dalam Alquran yaitu: Tarbiyah, Ta'alim dan Taadib.

Dalam rangka membangun peradaban umat manusia yang berkesinambungan menurut Al Qur'an melalui kegiatan membaca seperti tercantum dalam Alquran surah Al-Alaq ayat 1 (bacalah).

Ahli pendidikan Islam bersepakat bahwa ayat ini diturunkan oleh Allah sangat berhubungan dengan pendidikan. Proses dakwah Rasulullahpun dalam menyebarkan Islam dan membangun peradaban tidak lepas dari kegiatan pendidikan. Rasulullah mendidik para sahabatnya di rumah Ar qam bin Arqam. Pendidikan adalah sebuah proses untuk melahirkan suatu generasi yang diharapkan mampu membangun peradaban sesuai zamannya. Peran pendidikan dalam melahirkan sebuah generasi tidaklah cukup tanpa disertai suatu teori atau konsep yang benar. Apabila kita menerima teori ilmiah empiris sebagai sebuah paradigma dalam teori pendidikan, maka disadari atau tidak berarti kita telah meninggalkan hal-hal yang bersifat metafisis seperti dijelaskan di dalam Al Qur'an dan Sunnah. ${ }^{2}$

Pendidikan Islam memiliki kejelasan tujuan yang ingin dicapai. Hal itu bisa dimengerti karena tujuan pendidikan mempunyai kedudukan yang amat penting, karena didasarkan kepada Al Qur'an dan As Sunnah. Berangkat dari pengertian inilah akan menjadikan pondasi yang kuat menyangkut konsep bangunan pendidikan itu sendiri. Istilah Tarbiyah, Ta'lim dan ta'dib akan memberikan

\footnotetext{
${ }^{2}$ Nyimas Hartini, diakses pada tanggal 18 Oktober 2020 pada website makalah pai pasca iain: makalah filsafat pendidikan islam (makalahpascaiain.blogspot.com)
} 
pemahaman yang utuh, mengingat istilah tidaklah bebas nilai akan tetapi penuh dengan nilai-nilai yang mengikutinya. Dalam hal pendidikan, berdasarkan pada hadis dikenal dengan beberapa istilah yang dianggap mewakili pengertian tersebut. Hal tersebut disebabkan istilah pendidikan tidak disebutkan secara langsung dalam Alquran dan Al hadis. Sebenarnya, banyak istilah yang dianggap mendekati makna pendidikan, diantaranya al tansyi'ah, al islah, al ta'dib atau al adab, al tahzib, al tahir, al tazkiyyah, al ta'lim, al siyasah, al nash wa al irsyad dan al akhlaq. bahkan sumber lain menambahkan dengan istilah at Tarbiyin dan at Tadris. Namun, dalam komfrensi Islam dunia pertama mengenai pendidikan Islam pada tahun 1977, menegaskan bahwa pendidikan didefinisikan sebagai Al Tarbiyah, Al Ta'lim dan Al Ta'dib secara bersama-sama.

Pokok masalah kajian ini adalah konsep pendidikan menurut Alquran.Seperti disebutkan di atas bahwa berdasarkan konferensi Islam dunia pertma telah disetujui bahwa konsep pendidikan dalam Islam ada tiga yakni Tarbiyah, Ta'alim dan Ta'adib.

Berdasarkan latar belakang diatas penulis ingin mengungkapkan dua hal yaitu apa yang dimaksud dengan Tarbiyah, Ta'lim dan Ta'dib ? dan Bagaimanakah analisis perbandingan antara konsep ta'lim', ta'dib dan tarbiyah ?

\section{Penjabaran Tiga Konsep Pendidikan}

Pada bagian ini penulis akan menjelaskan tiga konsep pendidikan yang dijelaskan satu persatu satu dalam artikel ini. Sehingga penjelasannya akan lebih komprehensif.

\section{Penjelasan Al Tarbiyah}

Secara bahasa kata tarbiyah dengaan segala derifasinya memiliki beberapa pengertian. التربية . التربة, artinya " Pengalaman" artinya " Latihan" اتربية artinya percobaan atau eksperimen" dan artinya Pendidikan.

Menurut penyelidikan para ahli lughawi bahwa kata Tarbiyah berasal dari kata رب رب artinya memelihara. Dari sinilah kemudian ada pendapat bahwa kata rabba-yarbu artinya bertambah, 
tumbuh, dan 'rabbiya- yarbaa' berarti menjadi besar. Kata 'rabbayarubbu' artinya memperbaiki, menguasai urusan, menuntun, menjaga, dan memelihara.

Menurut Abdurrahman al-Nahlawi bahwa dalam Kamus Bahasa Arab, lafal al-Tarbiyah berasal dan tiga kata, yaitu:

Pertama: raba yarbu yang berarti bertambah dan bertumbuh. Makna ini dapat dilihat dan firman Allah:

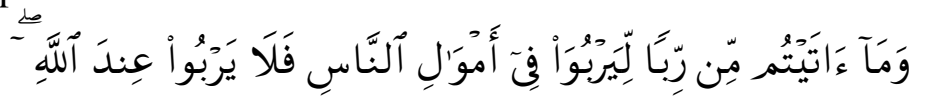

Terjemahnya :

39. dan sesuatu Riba (tambahan) yang kamu berikan agar Dia bertambah pada harta manusia, Maka Riba itu tidak menambah pada sisi Allah. (QS Al-Rum: 39).

Kedua: rabiya yarba dengan wazan (bentuk) khafiya yakhfa yang berarti: menjadi besar.

Ketiga: rabba yarubbudengan wazan (bentuk) madda yamuddu yang berarti memperbaiki, menguasai urusan, menuntun, menjaga dan memelihara. Dalam matan hadis yang berkaitan dengan al Tarbiyah kata Tarbiyah diartikan dengan perkara yang menguntungkan.

Dalam Kitab Manjhaj Tarbiyah Ibnu Qayyim ole Dr.Hasan bin Ali Hasan Al Hijazy, ahli bahasa : Muzaidi Hasbullah dijelaskan bahwa kata Tarbiyah berasal dari kata " Rabba "3 Perubahan sakal pada kata ini menyebabkan perubahan arti. Jika sakalnya fatha yaitu Rabba artinya mendidik, merawat, memimpin, mengumpulkan, menjaga, memperbaiki, mengembangkan dan sebagainya ".4 Bukan hanya itu perubahan makna juga dapat terjadi pada sakal fatha tetapi maknaya ditentukan kata sesudahnya. Misalnya dikatakan " Rabba Al Rajulu Al walada dan rabba al Qauma ". Kata pertama

\footnotetext{
${ }^{3}$ Muzaidi Hasbullah, Manhaj Tarbiyah Ibnu Qayyim ( Pustaka Al Kautsar : Perbit Buku Islam Utama : Jakrta Timur,2001), h.74

${ }^{4}$ Muzaidi Hasbullah, Manhaj Tarbiyah Ibnu Qayyim (Jakarta: Pustaka Al Kautsar, 2001), h.74
} 
artinya seorang laki-laki itu merawat anaknya. Sedangkan kata yang kedua artinya seorang laki-laki itu pemimpin suatu kaum. ${ }^{5}$ Selanjutnya bersakal dhamma $A r R a b b u$ artinya merajai, menjadi tuan, yang mendidik, yang menjadi wali, yang memberi nikmat, yang mengatur dan yang merawat. ${ }^{6}$ Kemudian jika bersakal kasrah Ar Rabbi artinya " seorang alim yang mengajar manusia dengan kecilnya ilmu sebelum besarnya ilmu “7

Berangkat dari beberapa pengertian tarbiyah menurut pembahasan di atas dapatlah dipahami bahwa tarbiyah adalah bimbingan dan tuntunan kepada peserta didik dengan merawat, mengembangkan potensi yang dimilikinya.

Ibnu Qayyim berkata bahwa " Tarbiyah adalah bimbingan yang diberikan kepada peserta didik berdasarkan ilmu seperti seorang ayah mendidik anak-anaknya"8 Pendapat lain mengatakan bahwa Kata "tarbiyah"merupakan masdar dari rabba, yurabbiy, tarbiyah dengan wazan fa'ala, yufa'ilu, tafilan". Selanjutnya Kata Tarbiyah juga ditemukan dalam Alquran Surat Al-Isra'17:24
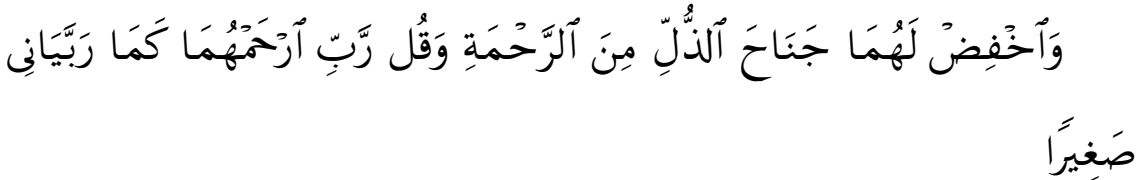

Terjemahnya: dan rendahkanlah dirimu terhadap mereka berdua dengan penuh kesayangan dan ucapkanlah: "Wahai

${ }^{5}$ Muzaidi Hasbullah, Manhaj Tarbiyah Ibnu Qayyim (Jakarta: Pustaka Al Kautsar, 2001), h.75

${ }^{6}$ Lihat Mu'jamul Washit

${ }^{7}$ Dimaksud dengan kecilnya ilmu adalah kunci masalahnya secara golobalnya, sedang besarnya ilmu adalah permasalahannya secara detail.Lihat Kamus Lisanul Arab, Ibnu Mandzur dan Fathul Bari, Ibnu Hajar Al Asqalani.Lihat juga Kitab Tashil Lil Ulumit Tanzil, Muhammad bin Ahmad bin Jazzi Al Kalaby.

${ }^{8}$ Muzaidi Hasbullah, Manhaj Tarbiyah Ibnu Qayyim (Jakarta Timur: Penerbit Buku Islam Utama, 2001),h.76

${ }^{9}$ Hanan Anshar, Jurnal Ta'dib 
Tuhanku, kasihilah mereka keduanya, sebagaimana mereka berdua telah mendidik aku waktu kecil"."

Berangkat dari firman di atas, kemudian ada pendapat bahwa kata rabba-yarbu artinya bertambah, tumbuh, dan 'rabbiyayarbaa' berarti menjadi besar. Kata 'rabba-yarubbu' artinya memperbaiki, menguasai urusan, menuntun, menjaga, dan memelihara.

Kembali di angkat pendapat Abdurrahman al-Nahlawi di atas bahwa dalam Kamus Bahasa Arab, lafal al-Tarbiyah berasal dan tiga kata, yaitu:

Pertama: raba yarbuyang berarti bertambah dan bertumbuh. Makna ini dapat dilihat dan firman Allah:

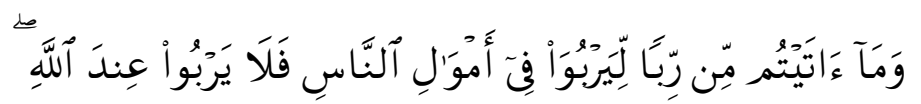

Terjemahnya :

39. dan sesuatu Riba (tambahan) yang kamu berikan agar Dia bertambah pada harta manusia, Maka Riba itu tidak menambah pada sisi Allah.

Kedua: rabiya yarbadengan mwazan (bentuk) khafiya yakhfa yang berarti: menjadi besar. Berdasarkan makna inilah Ibn aI-'Arabi mengatakan:

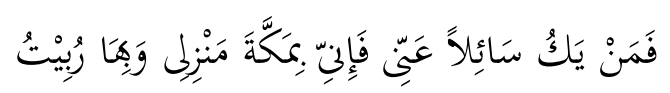

" Jika orang bertanya tentang diriku, maka Mekah adalah tempat tinggalku dan di situlah aku dibesarkan ".

Ketiga: rabba yarubbu dengan wazan (bentuk) madda yamuddu yang berarti memperbaiki, menguasai urusan, menuntun, menjaga dan memelihara. Makna ini antara lain ditunjukkan oleh

${ }^{10}$ Departemen Agama RI,Alquran dan Terjemahnya (Departemen Agama RI,2003), h. 143 
perkataan Hasan bin Tsabit, sebagaimana yang ditulis oleh Ibn alManzhur dalam "Iisan al-'Arab:"

\section{Penjelasan al-Ta'lim}

Secara bahasa (etimologi), kata ta'lim ( تعليم ) merupakan bentuk masdar (kata kerja yang dibendakan). Kata talim berasal dari kata kerja 'allama - yu'allimu - ta'liman ( علم - يعلم - عeيما) yang sebagian ahli pendidikan mengartikannya dengan pengajaran. ${ }^{12}$

Dalam al quran, kata ta'lim dapat ditemukan di berbagai surat. Salah satu di antaranya pada surah al Baqarah ayat $31 .^{13}$
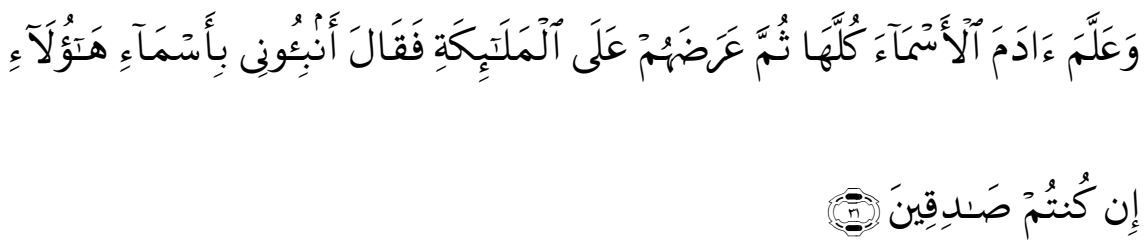

Terjemahnya :

Dia mengajarkan kepada Adam Nama-nama (benda-benda) seluruhnya, kemudian mengemukakannya kepada Para Malaikat lalu berfirman: "Sebutkanlah kepada-Ku nama benda-benda itu jika kamu mamang benar orang-orang yang benar!"

Menurut istilah (terminologi) kata ta'lim adalah merujuk kepada pengajaran yang bersifat pemberian atau penyampaian pengertian, pengetahuan dan ketrampilan. Selanjutnya pendapat lain mengatakan bahwa Ta'lim memiliki arti memberitahukan

${ }^{11}$ Ibnu Manzhur, Lisan al-Arab Jilid 4 (Beirut: Dar al-Ihya al-Turath, 1984), h. 254.

${ }^{12}$ Ahmad Wardon Munawir, Kamus Al-Munawir (Surabaya: Pustaka Progresif, 1984), h. 476.

${ }^{13}$ QS.Albaqarah :31 
sesuatu kepada seseorang yang belum tahu. Dasarnya adalah firman Allah Swt. dalam Alquran surah Albaqarah ayat 129. ${ }^{14}$

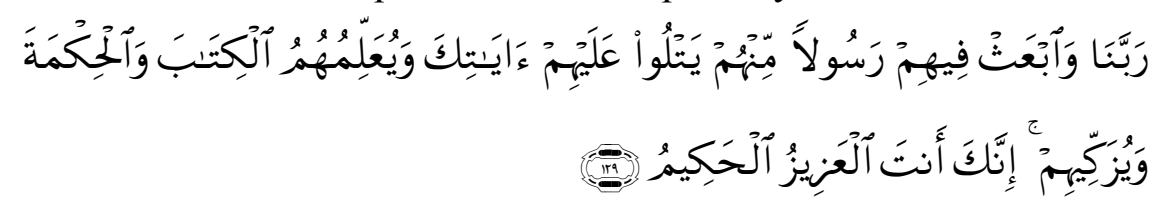

Terjemahnya :

129. Ya Tuhan Kami, utuslah untuk mereka sesorang Rasul dari kalangan mereka, yang akan membacakan kepada mereka ayat-ayat Engkau, dan mengajarkan kepada mereka Al kitab (Al Quran) dan Al-Hikmah (As-Sunnah) serta mensucikan mereka. Sesungguhnya Engkaulah yang Maha Kuasa lagi Maha Bijaksana.

Selanjutnya Rasulullah saw dalam salah satu sabdanya yang artinya "Barang siapa yang mengajarkan suatu ilmu maka dia memperoleh pahala orang yang mengamalkannya"

Menurut kebanyakan pakar pendidikan mengatakan bahwa pada umumnya makna kata ta'lim terbatas pada pengajaran dan pendidikan kognitif semata.Tidak merangkul aspek religi, etika dan afektif serta psikomotor.Ini membuktiktikan bahwa konsep ta'lim hanya mengedepankan proses pengalihan ilmu pengetahuan dari pengajar (mu'alim) dan yang diajar (muta'alim). Pandangan ini didasarkan pada firman Allah Swt. surat Yusuf, ayat 6, ${ }^{15}$

${ }^{14}$ QS.Albaqarah : 129

${ }^{15}$ Tulisan ini dikutip pada tanggal 13 oktober 2020 pada website hadits tarbawi: tarbiyah, ta'lim dan ta'dib dalam al-qur'an da assunnahhaditstarbawielghazy.blogspot.com. 


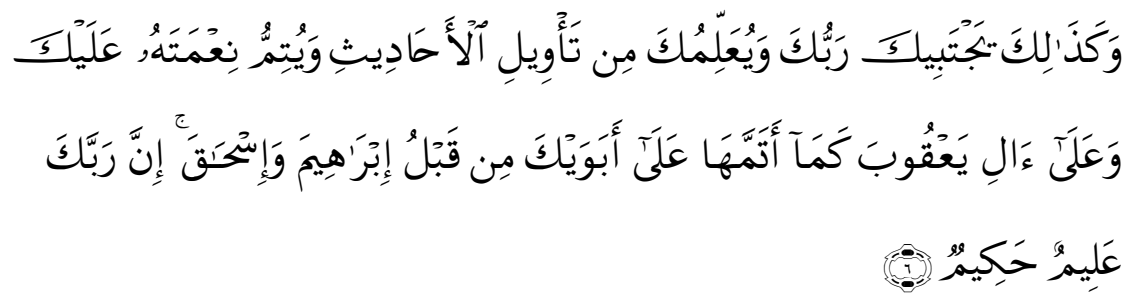

Terjemahnya : dan Demikianlah Tuhanmu, memilih kamu (untuk menjadi Nabi) dan diajarkan-Nya kepadamu sebahagian dari ta'bir mimpi-mimpi dan disempurnakan-Nya nikmat-Nya kepadamu dan kepada keluarga Ya'qub, sebagaimana Dia telah menyempurnakan nikmat-Nya kepada dua orang bapakmu[743] sebelum itu, (yaitu) Ibrahim dan Ishak. Sesungguhnya Tuhanmu Maha mengetahui lagi Maha Bijaksana.

Dalam ayat ini dengan gamblang Allah menyebutkan bahwa diajarkan atau dialihkan kepada Nabi adalah tabir mimpi. Sedangkan pada surat Al Maidah ayat 4, ilmu yang dimaksud adalah ilmu berburu.Seperti firman Allah Swt.berikut ini

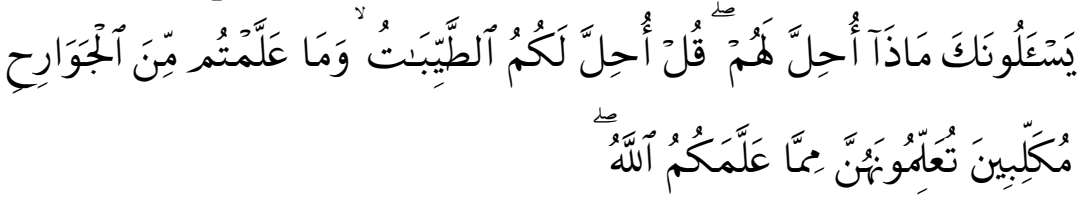

Terjemahnya :

Mereka menanyakan kepadamu: "Apakah yang Dihalalkan bagi mereka?". Katakanlah: "Dihalalkan bagimu yang baik-baik dan (buruan yang ditangkap) oleh binatang buas yang telah kamu ajar dengan melatih nya untuk berburu; kamu mengajarnya menurut apa yang telah diajarkan Allah kepadamu.

Kemudian sebagian dari para ahli pendidikan berkata bahwa kata Ta'lim juga mewakili ungkapan proses penyampaian materi pelajaran dari pendidik kepada peserta didik dari tidak tahu menjadi tahu. Hal tersebut didasarkan dari perkataan Sa'ad bin Waqash, menganjurkan agar anak-anak yang tidak tahu tentang riwayat Rasulullah saw. diajar atau diberi pelajaran sehingga mereka menjadi tahu. Berdasarkan ayat di atas dapat dipahami bahwa kata 
ta'lim menunjukkan kepada pengalihan materi ajar oleh pendidik kepada peserta didik.

\section{Penjelasan Al Ta'dib}

Secara bahasa, kata ta'dib merupakan bentuk masdar (kata kerja dibendakan).Asal kata al ta'dib adalah kata kerja addabayuaddibu-ta'diban, yang berarti mengajarkan sopan santun. Sedangkan menurut istilah ta'dib dapat diartikan sebagai proses mendidik yang memfokuskan kepada pembinaan dan penyempurnaan akhlak atau budi pekerti peserta didik. ${ }^{16}$

Menurut Prof. Wan Daud, Al-Qur'an menegaskan bahwa contoh ideal bagi orang yang beradab adalah Nabi Muhammad saw yang oleh kebanyakan sarjana muslim disebut sebagai manusia sempurna atau manusia universal (al-insān al-kulīi). Oleh karenanya pengaturan administrasi pendidikan dan ilmu pengetahuan dalam sistem pendidikan Islam haruslah merefleksikan manusia yang sempurna.

Fakta bahwa pendidikan Nabi Muhammad saw dijadikan Allah sebagai pendidik yang terbaik didukung oleh Alquran yang menunjukkan kedudukan rasulullah saw yang mulia, suri tauladan yang baik. Ini kemudian dikuatkan oleh hadis Nabi Muhammad saw yang berbunyi :

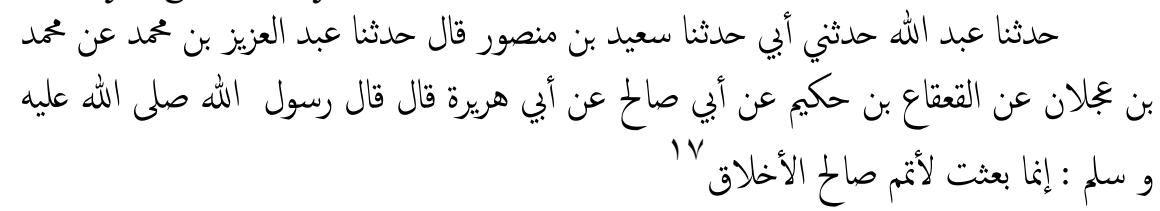

${ }^{16}$ Tulisan ini diakses pada tanggal 16 Oktober pada website aris utomo: tarbiyah, ta'lim dan ta'dib (arisutomotulungagung.blogspot.com)

${ }^{17}$ Ahmad bin Hanbal, Musnad Ahmad bin Hanbal Jilid 1 (Beirut: Dar al-Kitab, 2005), h. 56 
Artinya :

Dari Abdullah Sesungguhnya aku diutus untuk menyempurnakan ahlaq.

Dalam hadis di atas terdapat misi untuk menyempurnakan akhlak manusia. Seseorang yang paling sempurna imannya menurut Rasulullah saw adalah orang yang paling baik akhlaknya.

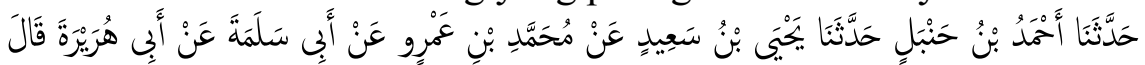

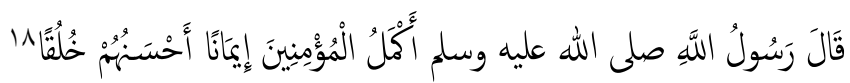

Terjemahannya

Telah menceritakan kepada kami Ahmad bin Hanbal, dari Yahya bin Said, dair Muhammad bin Amrin dari Abi Salamah dari Abu Hurairah Rasululah saw berkata Mukmin yang lebih sempurna keimanannya adalah mukmin yang paling baik ahlaqnya.

Dalam hal ini jika seorang itu telah beradab, secara otomatis telah memiliki ilmu benar serta mempunyai tujuan kehidupan yang jelas mencakup spritual dan material. Oleh karena itu, pemilihan istilah- istilah kunci dalam dunia pendidikan Islam sangat menentukan perkembangannya pendidikan Islam di masa depan.

Ta'dib ini dapat mencetak manusia yang beradab, dapat terhindar dari sifat- sifat kezhaliman (zhulm), kebodohan (jahl), dan kegilaan (junun). Sebab ilmu tidak dapat dipindahkan atau diajarkan (transfer of knowledge) dengan sempurna oleh seorang guru kepada muridnya dalam proses pendidikan kecuali jika telah mempunyai adab terhadap berbagai bidang disiplin ilmu pengetahuan. ${ }^{19}$

${ }^{18}$ Hanbal, Musnad Ahmad bin Hanbal, h. 45

${ }^{19}$ Tulisan ini diambil pada tanggal 17 oktober 2020 pada website: Okta Hardianti HR: Pengertian Ta'lim ,Ta'dib dan Tarbiyah (oktahr.blogspot.com) 


\section{Analisis Perbandingan Konsep Tarbiyah, Ta'lim dan Ta'dib}

Istilah ta'Tim', ta'dib dan tarbiyah jika ditinjau dari segi penekanannya terdapat titik perbedaan antara satu dengan lainnya, namun apabila dilihat dari unsur kandungannya, terdapat keterkaitan yang saling mengikat satu sama lain, yakni dalam hal memelihara dan mendidik peserta didik.

Pada kata ta'lim, aksentuasinya kepada penyampain materi pelajaran kepada peserta didik secara benar untuk membentuk pemahaman, pengertian, tanggung jawab kepada peseerta didik. Oleh karena itu ta'lim di sini mencakup aspek-aspek pengetahuan dan ketrampilan yang di butuhkan seseorang dalam hidupnya dan pedoman perilaku yang baik. Sedangkan pada tarbiyah, aksentuasinya difokuskan kepada bimbingan dan pemeliharaan jasmani dan rohani peserta didik untuk mencapai kedewaannya secara maksimal, berdaya guna kepada agama, bangsa dan negara dan tumbuh pribadinya secara sempurna. Sementara pada konsep ta'dib, aksentuasinya kepada penguasaan peserta didik terhadap ilmu pengetahuan dan teknologi secara benar dan diwujudkan dalam amal baik dan akhlakulkarimah. Dengan pemaparan ketiga konsep pendidikan menurut Alquran di atas dapat dipahami bahwa Alquran menawarkan tiga konsep pendidikan. Pertama konsep tarbiyah yakni kegiatan pembelajaran yang berorientasi kepada pembentukan pembekalan konitif, afektif dan psikomotor peserta didik.Untuk mencapai itu diperlukan teknik metode dan materi pelajaran yang mendukung tercapainya tujuan pembelajaran. Kedua konsep ta'lim adalah kegiatan pendidik yang mentranfes ilmu pengetahuan dan teknologi kepada peserta didik dengan tidak mempertimbangkan penguasaan dan manfaatnya. Peseta didiklah yang menentukan untuk apa yang mempelajari sesuatu.Ketiga adalah konsep ta'dib secara khusus membina dan membing pserta didik kepada terbentuknya akhlakul karimah dengan dipenuhi oleh penguasaan ilmu pengetahuan dan teknologi menurut zamannya. ${ }^{20}$

${ }^{20}$ Tulisan ini diambil dari website pada tanggal 17 November 2020 pada website .uasspi1: Pengertian ta'lim, ta'dib, dan tarbiyah. 
Saat ini umat manusia sedang menghadapi perubahan yang begitu cepat yang timbul sebagai dampak dari kemajuan ilmu pengetahuan dan teknologi, kajian-kajian mengenai konsep pendidikan menjadi tetap menarik dan bahkan, tidak dapat dihindarkan. Apalagi jika hal tersebut didasarkan pada asumsi bahwa segala problem itu berpangkal dari suatu penerapan konsep pendidikan yang mendorong progresivitas ilmu pengetahuan dan teknologi yang tidak terkendali. ${ }^{21}$

Dalam dunia Islam juga muncul berbagai issu tentang krisis pendidikan serta problem lainnya yang dengan sangat mendesak menuntut suatu pemecahan berupa terwujudnya suatu sistem pendidikan yang didasarkan atas konsep Islam. Dalam hal ini banyak tokoh-tokoh pendidikan Muslim telah berusaha menyusun suatu konsep pendidikan yang menurut keyakinan mereka sudah dapat dikatakan relevan dengan tuntutan umat manusia dan perkembangan masa kini. Syed M. Naquib al-Attas seorang pemikir pendidikan yang concern terhadap pendidikan. Dalam karya monumentalnya " The Concept of Education In Islam: A Framework for an Islamic Philosophy of Education", dan dalam Konferensi Dunia Pertama dan Kedua tentang Pendidikan Islam di Mekkah dan Islamabad, al-Attas mencetuskan dan menawarkan bahwa konsep atau istilah yang tepat, benar, dan relevan untuk pendidikan adalah konsep ta'dib, bukan ta'lim, dan tarbiyah, ataupun konsep yang lainnya. Karena, menurut al-Attas, konsep tarbiyah hanya menekankan atau menyinggung aspek fisikal dan emosional manusia (karena proses tarbiyah ini berlaku tidak hanya untuk manusia an sich, tetapi berlaku untuk hewan dan tumbuhtumbuhan, oleh karena itu konsep tarbiyah kurang tepat untuk istilah pendidikan bagi manusia). Sedangkan konsep ta'lim secara umum hanya menekankan pada transfer of knowledge (aspek kognitif) dan pengajaran. Agar proses pendidikan berjalan secara komprehensif yakni mencakup ranah kognitif, psikomotorik dan ranah afektif, maka al-Attas menawarkan konsep ta'dib. ${ }^{22}$

${ }^{21}$ Tulisan ini diambil dari website pada tanggal 17 Oktober 2020 pada website Makalah PAI Pasca IAIN: 2015 (makalahpascaiain.blogspot.com)

${ }^{22}$ Aris utomo tulisan ini diakses pada tanggal 18 Oktober pada website: tarbiyah, ta'lim dan ta'dib (arisutomotulungagung.blogspot.com) 


\section{Kesimpulan}

Penggunaan konsep pendidikan berdasar Alquran menjadi penting, dalam pendidikan. Konsep pendidikan yang tepat dapat mendasari tujuan, materi, metode, kurikulum dan evaluasi pendidikan itu sendiri.

Konsep tarbiyah dan ta'lim adalah dua istilah yang satu sama lain memiliki kaitan erat dengan kegiatan pendidikan. Proses pengembangan diri dan pengajaran adalah bagian penting dalam pendidikan untuk mencapai tujuan manusia sebagai hamba Allah.

Berdasarkan uruaian dan penjelasan diatas ternyata terdapat tiga konsep pendidikan dalam Al-Qur' an yang tidak bisa dipisahkan antar satu dengan yang lain yaitu konsep ta'dib, ta'lim dan tarbiyyah. Tiga konsep ini salling melengkapi didalamnya ada pengajaran, pendidikan dan pembelajaran.

Menurut analisisa yang terkandung dari tiga konsep pendidikan yang dikemukakan dalamkajian ini, istilah At-tarbiyah lebih tepat digunakan sebagai kata yang mewakili pendidikan, hal ini memiliki landas dan filosofis seperti dijelaskan oleh Allah dalam Q.S Ali Imran ayat 79. 


\section{Daftar Pustaka}

Abu Zahra, Ushul Fiqh: Bab Sumber-Sumber Hukum Islam Surabaya: Gramedia Insani, 2001

Adz-Dzahabi, Muhanmmad Husein, Siyar A'lam An-Nubala, Beirut: Dar al-Kutub, 1985.

Ahmad Al-Ghamidi Al-Baihaqi wa Mauqifuhu min Al-Ilahiyya

Al-Baihaqi. Adhwa As-Salaf. Al-Madkhal ila As-Sunan Al-Kubra.

Ashidiqye, Hasbi. Pengantar Hukum Islam. Semarang: PT.Thaputra, 1967.

Cece Wijaya, Pendidikan Remedial Sarana Pengembangan Mutu Sumber Daya Manusia. Bandung: Rosda Karya, 2007.

Muzaidi Hasbullah, Manhaj Tarbiyah Ibnu Qayyim. Jakarta: Pustaka al-Kautsar. 2001.

R.L.Shamnon, Gagasan Baru Dalam Pendidikan. Jakarta: Mutiara 1967.

Yahya, Ahmad. Dasar-dasar Pendidikan Agama Islam .Semarang: Raja Grafindo, 2008. Offser, Semarang.

Zahra, Abu. Ushul Fiqh: Bab Sumber-Sumber Hukum Islam. Surabaya: PT.Gramedia, 2001. 